\title{
OPINIÕES DE FUNCIONÁRIOS DE PARQUES BRASILEIROS SOBRE AÇÕES DE MANEJO EM LOCALIDADES RURAIS SITUADAS NO SEU ENTORNO E INTERIOR
}

\author{
Shirley Noely Hauff*, Miguel Serediuk Milano** \\ * Bióloga, Dr ${ }^{\mathrm{a}}$, WWF-Brasil - shirley@wwf.org.br \\ ** Eng. Florestal, Dr., FBPN - milano@fundacaoboticario.org.br \\ Recebido para publicação: 10/02/2005 - Aceito para publicação: 09/06/2005
}

\begin{abstract}
Resumo
Opiniões de funcionários de parques brasileiros sobre ações de manejo em localidades rurais situadas no seu entorno e interior. Analisam-se as ações de manejo e extensão desenvolvidas em localidades rurais existentes dentro e no entorno de seis unidades de conservação brasileiras manejadas como parque e as opiniões de seus funcionários. A estes foi aplicado questionário para identificar as atividades de moradores dessas localidades, as ações desenvolvidas e as opiniões sobre seus resultados. Os dados foram analisados por unidade de conservação, de forma global e por comparação entre elas. Segundo os funcionários, os moradores praticam atividades agropecuárias e extrativistas, bem como foram desenvolvidos sete tipos de ações de manejo e extensão pelas administrações. As ações de controle foram as mais citadas e avaliadas com melhor resultado. Os resultados positivos dessas ações foram relacionados, principalmente, ao medo da fiscalização e punição, e os negativos, à falta de condições de trabalho na unidade. A maioria das unidades estudadas apresentou reduzido número de funcionários e alguns deles demonstraram conhecimento ou concepções inadequados sobre a categoria parque.

Palavras-chave: Unidades de conservação; ações de extensão; proteção integral.
\end{abstract}

\begin{abstract}
Brazilian parks personnel opinions about management of rural communities inside and surrounding protected areas. This research evaluates management developed in rural communities inside and surrounding six Brazilian parks, and the opinions of their respective personnel as well. Employees of the parks filled in questionnaires regarding production activities carried out by local communities, developed management and their opinions about such actions results. Results of each park were analyzed and compared, as a whole and separately. Activities carried out by local communities are based on extraction, agriculture and ranching. Seven different ways of management were developed, and control activities were the most cited and better evaluated. The positive results were mainly related to fear of control and punishment, and the negative ones related to lack of working conditions in parks. The majority of parks presented very few employees, and among those people some of them presented inappropriate knowledge or concepts of park category.

Keywords: Protected areas; parks; management; strict-use protected areas.
\end{abstract}

\section{INTRODUÇÃO}

De acordo com a União Mundial pela Natureza (UICN, 1993), mesmo que as unidades de conservação ocupem grandes extensões de paisagens relativamente desabitadas, haverá pessoas vivendo ou retirando seu sustento delas, o que pode gerar conflitos entre as áreas protegidas e as comunidades locais. Para superá-los, a UICN (1993a) sugere a integração do diálogo com grupos de interesse em todas as atividades de planejamento e manejo de unidades de conservação, bem como de suas zonas de amortecimento. Contudo, as unidades de conservação brasileiras enfrentam diversos problemas, sendo comum a falta de regularização fundiária, a carência de pessoal capacitado, precárias situações institucionais, além de processos distorcidos para a elaboração e implementação de planos de manejo (Jorge Pádua, 1997; Milano, 1997). Além disso, raramente os administradores são treinados nas 
habilidades necessárias para o trabalho com comunidades (Oldfield, 1988; Costa Rica, 1990; Milano, 1991), sendo comum, no Brasil, a ausência de competência (mandato), pessoal e/ou orçamento para o estabelecimento de mudanças nas áreas rurais periféricas às unidades (Barborak, 1997).

Conforme Milano (1991), as pressões de ocupação e exploração ilegal de recursos (caça, pesca, desmatamento e mineração) são os principais problemas das unidades de conservação de regiões povoadas, especialmente nos países em desenvolvimento. Para esse autor, as unidades situadas em territórios povoados têm se constituído em 'ilhas' "isoladas e cercadas por sistemas antropizados que, quando não produzem fortes pressões, no mínimo inviabilizam parcialmente certos objetivos de conservação" (Milano, 1991, p. 19). Oldfield (1988) afirma que freqüentemente a proteção legal não tem sido suficiente para manter a integridade das unidades, mesmo quando nelas existem atividades de manejo. A agricultura invade espaços protegidos, a exploração ilegal de produtos florestais é efetuada dentro de seus limites, as leis são desobedecidas, o controle fracassa e a unidade é gradualmente destruída.

A União Mundial pela Natureza (UICN, 1993) declara que as áreas periféricas ou de entorno das unidades de conservação devem, além de voltar-se para a proteção dos recursos essenciais, constituir-se em espaços voltados a atividades economicamente viáveis, culturalmente aceitáveis e ecologicamente compatíveis. Ao cumprirem essas finalidades e reduzirem os impactos negativos das atividades externas às unidades, essas áreas periféricas assumem o papel de zonas tampão (buffer zones) ou de amortecimento. A Lei Federal no 9.885/2000, que institui o SNUC (Brasil, 2000), em seu Artigo 2º define zona de amortecimento como "o entorno de uma unidade de conservação, onde as atividades humanas estão sujeitas a normas e restrições específicas, com o propósito de minimizar os impactos negativos sobre a unidade". Kamstra (1994) afirma que em todas as definições de zona de amortecimento a prioridade é garantir proteção à biodiversidade, enquanto que benefícios para os habitantes locais assumem importância secundária. Contudo, o autor complementa que freqüentemente esse conceito é utilizado incorretamente e que, até o momento, existe apenas no papel. Esse autor identificou alguns poucos modelos de aplicação de zona de amortecimento, citando que, na análise de quase 20 trabalhos, Wells et al. (1992) encontraram uma grande diferença entre o planejamento dessas zonas e sua aplicação.

Lucas (1992) afirma que, nos processos de integração das unidades de conservação ao desenvolvimento socioeconômico, é fundamental conscientizar e convencer os habitantes sobre a importância da natureza e da biodiversidade, tanto por seus valores intrínsecos, humanos ou de sustentação da própria vida. Miller (1979) e Milano (1997), ao descreverem a elaboração dos programas de manejo no processo de planejamento de unidades de conservação, orientam para a definição de subprogramas de extensão que definam atividades que visem integrá-las com as comunidades locais. Dourojeanni (1997) adverte que, em tais processos, a inobservância dos objetivos de criação e manejo das unidades de conservação tende a resultar na alienação do território ou na destruição de seus recursos, ou seja, na perda de sua função essencial. Para evitar animosidades entre os grupos de interesse e prejuízos à conservação, o autor sugere que a participação siga algumas regras básicas, entre as quais destaca que o processo deve restringir-se ao grau de liberdade correspondente à categoria de manejo da área, sem violálo. Em caso de necessidade, ressalta que se deve alterar a categoria da unidade antes de alterar seus objetivos de manejo. Além disso, afirma que a participação deve fundamentar-se em boas informações sobre os fatos, cuja responsabilidade é da própria administração da unidade de conservação. Mackinnon (1993) afirma que a maneira de se aproximar das comunidades deve ser orientada pela transferência de informações sobre a importância e os benefícios da unidade de conservação, buscando realizar atividades que cativem a confiança e alterem a conduta das pessoas frente aos recursos naturais (Moore, 1993; Lewis, 1993).

Além disso, Lewis (1993) discute que os conflitos entre unidades de conservação e populações locais devem ser entendidos e avaliados quanto às suas características dentro da perspectiva dos interesses mútuos e de uma estratégia de ação que vise sua resolução. Wells et al. (1992), analisando a aplicação de projetos integrados de conservação e desenvolvimento (Integrated Conservation-Development Projects ICDPs), demonstraram uma maior efetividade de implantação em projetos com escala compatível à realidade da unidade e à sua capacidade de viabilização. Para os autores, os projetos devem possuir seriedade nos compromissos políticos de apoio, legislação condizente aos objetivos propostos, convênios institucionais realistas em sua administração, compatibilidade com o desenvolvimento regional, atenção aos direitos de propriedade e de acesso aos recursos pelos beneficiários do projeto, bem como 
compromisso de reorientação institucional.

Nesta pesquisa, objetivou-se identificar a opinião de funcionários sobre as ações de manejo e extensão efetuadas pelas administrações de seis unidades de conservação da categoria parque, ou manejadas como tal, junto a comunidades rurais existentes dentro e no entorno delas. Especificamente, visou-se:

- identificar as atividades desenvolvidas pelos moradores e a opinião dos funcionários sobre a adequação dessas atividades em relação aos objetivos da unidade;

- identificar as ações de extensão e de manejo relacionadas às atividades desenvolvidas pelos moradores;

- identificar a opinião dos funcionários das unidades sobre os resultados dessas ações; e

- identificar as ações e os procedimentos mais efetivos para a adequada implementação das unidades.

\section{METODOLOGIA}

Para alcançar os objetivos previstos, foram selecionadas unidades de conservação segundo os seguintes critérios, em ordem de prioridade:

- unidade de conservação de proteção integral;

- categoria de manejo parque para homogeneidade, pelo maior número e, normalmente, por ter mais ações de manejo implementadas que as outras categorias de proteção integral;

- aplicação de ações de manejo e de extensão pelas administrações das unidades nas localidades rurais há pelo menos dois anos;

- distribuição geográfica abrangendo maior diversidade possível de biomas e regiões geopolíticas brasileiras; e

- interesse e disposição da administração da unidade em cooperar com a pesquisa.

A compatibilização desses diferentes critérios possibilitou a seleção das unidades: Reserva Natural Salto Morato (RNSM), Parque Estadual da Ilha do Cardoso (PEIC), Parque Nacional do Jaú (PNJ), Parque Nacional da Serra da Capivara (PNSC), Parque Nacional Grande Sertão Veredas (PNGSV) e Parque Nacional Chapada dos Veadeiros (PNCV), cujas características são apresentadas na Tabela 1.

Tabela 1. Lista das unidades de conservação e suas características segundo os critérios utilizados para sua seleção.

Table 1. List of parks and their characteristics according to the criteria used for their selection.

\begin{tabular}{lcccccccc}
\hline $\begin{array}{l}\text { Nome da Unidade } \\
\text { de Conservação }\end{array}$ & $\begin{array}{c}\text { Categoria } \\
\text { de Manejo }\end{array}$ & $\begin{array}{c}\text { Início } \\
\text { da } \\
\text { Ação }\end{array}$ & Bioma & Região & UF & $\begin{array}{c}\text { Nível } \\
\text { Intitu- } \\
\text { cional }\end{array}$ & $\begin{array}{c}\text { Forma de } \\
\text { Gestão }\end{array}$ & $\begin{array}{c}\text { Organização } \\
\text { responsável }\end{array}$ \\
\hline $\begin{array}{l}\text { Reserva Natural } \\
\text { Salto Morato }\end{array}$ & $\begin{array}{c}\text { RPPN, manejo } \\
\text { de parque }\end{array}$ & 1996 & $\begin{array}{c}\text { Floresta } \\
\text { Atlântica }\end{array}$ & Sul & PR & $\begin{array}{c}\text { Privada } \\
3^{-} \text {setor }\end{array}$ & $\begin{array}{c}\text { Terceiro } \\
\text { setor }\end{array}$ & FBPN \\
\hline Ilha do Cardoso & Parque Estadual & 1997 & $\begin{array}{c}\text { Floresta } \\
\text { Atlântica }\end{array}$ & Sudeste & SP & $\begin{array}{c}\text { Pública } \\
\text { Estadual }\end{array}$ & Pública & IF - SP \\
\hline Jaú & Parque Nacional & 1995 & $\begin{array}{c}\text { Floresta } \\
\text { Amazônica }\end{array}$ & Norte & AM & $\begin{array}{c}\text { Pública } \\
\text { Federal }\end{array}$ & Parceria & IBAMA e FVA \\
\hline Serra da Capivara & Parque Nacional & 1991 & Caatinga & Nordeste & PI & $\begin{array}{c}\text { Pública } \\
\text { Federal }\end{array}$ & Co-gestão & $\begin{array}{c}\text { IBAMA e } \\
\text { FUMDHA }\end{array}$ \\
\hline $\begin{array}{l}\text { Grande Sertão } \\
\text { Veredas }\end{array}$ & Parque Nacional & 1990 & Cerrado & Sudeste & MG & $\begin{array}{c}\text { Pública } \\
\text { Federal }\end{array}$ & Co-gestão & $\begin{array}{c}\text { IBAMA e } \\
\text { FUNATURA }\end{array}$ \\
\hline $\begin{array}{l}\text { Chapada dos } \\
\text { Veadeiros }\end{array}$ & Parque Nacional & 1995 & Cerrado & $\begin{array}{c}\text { Centro- } \\
\text { Oeste }\end{array}$ & GO & $\begin{array}{c}\text { Pública } \\
\text { Federal }\end{array}$ & Parceria & $\begin{array}{c}\text { IBAMA e WWF- } \\
\text { Brasil }\end{array}$ \\
\hline
\end{tabular}

Efetuou-se pesquisa bibliográfica e de dados secundários sobre informações básicas de cada unidade e sobre as ações de extensão desenvolvidas junto aos moradores das localidades rurais. Como houve dificuldades na obtenção de informações antes da realização do trabalho de campo nas unidades, a 
maior parte dos dados foi obtido somente na visita às sedes das administrações, co-gestores e parceiros. Mesmo assim, informações bibliográficas sobre as ações desenvolvidas junto às comunidades foram insuficientes e, por isso, realizou-se entrevista com os responsáveis pela administração das unidades e pelo desenvolvimento dessas ações, para complementar sua descrição e caracterização. As entrevistas foram efetuadas antes da aplicação dos questionários, contudo, algumas informações ainda foram complementadas depois da realização das atividades de campo.

Elaborou-se questionário com perguntas com parte da resposta fechada (escolha de alternativas) e parte aberta (opiniões e justificativas sobre fatos e/ou procedimentos) para ser aplicado aos funcionários das unidades. Este abordou (1) o perfil do entrevistado (nome, gênero, idade, função, tempo de trabalho) e (2) opiniões sobre as formas de ocupação da terra e usos dos recursos dos moradores e sobre as ações de manejo e extensão desenvolvidas pelas administrações das unidades. No segundo item, foram solicitadas informações sobre as atividades desenvolvidas pelos moradores das localidades rurais antes e depois da criação da unidade. Para esse último caso, foi perguntado onde essas atividades são desenvolvidas, ou seja, se dentro dos limites da unidade ou em seu entorno, bem como qual a opinião sobre a adequação das atividades dos moradores aos objetivos da unidade (adequada, tolerável ou inadequada). Também foi perguntado se é realizada alguma ação de manejo ou extensão, por parte da unidade de conservação, para influenciar a forma de desenvolvimento dessas atividades dos moradores, qual o resultado alcançado pela ação (se obteve sucesso, sucesso parcial ou insucesso) e qual o motivo de tal resultado (parte aberta da pergunta). Para facilitar a compreensão, utilizou-se a palavra "atividade" para referir-se às atividades desenvolvidas pela comunidade e a palavra "ação" para ações desenvolvidas pelas administrações das unidades de conservação. A Figura 1 apresenta o modelo do questionário aplicado.

Figura 1. Modelo de questionário aplicado aos funcionários das unidades de conservação.

Figure 1. Questionnaire model applied to the parks' personnel.

\begin{tabular}{|c|c|c|c|c|c|c|}
\hline \multicolumn{7}{|c|}{ 1. IDENTIFICAÇÃO (PERFIL DO ENTREVISTADO) } \\
\hline \multicolumn{4}{|l|}{ Nome: } & \multicolumn{3}{|l|}{ Gênero: } \\
\hline \multicolumn{4}{|c|}{ Função no parque: } & \multicolumn{3}{|c|}{ Tempo no parque: } \\
\hline \multicolumn{7}{|c|}{ 2. FORMAS DE OCUPAÇÃO DA TERRA E USO DOS RECURSOS NATURAIS } \\
\hline Atividades & Tempo & Local & Classe & Ação de manejo ou extensão efetuada & Resultado & Motivo \\
\hline \multicolumn{7}{|c|}{ Agropecuária } \\
\hline & & & & & & \\
\hline \multicolumn{7}{|c|}{ Extrativismo } \\
\hline & & & & & & \\
\hline \multicolumn{7}{|l|}{ Rec. Fauna } \\
\hline & & & & & & \\
\hline \multicolumn{7}{|c|}{ Extr. Mineral } \\
\hline & & & & & & \\
\hline \multicolumn{7}{|c|}{ LEGENDA: } \\
\hline Atividade: & \multicolumn{6}{|c|}{ opinião - listar atividades desenvolvidas pelos moradores das localidades rurais } \\
\hline Tempo: & \multicolumn{6}{|c|}{ antes e depois da criação da unidade } \\
\hline Local: & \multicolumn{6}{|c|}{ dentro da unidade, no entorno da unidade } \\
\hline Classe: & \multicolumn{6}{|c|}{ adequação das atividades aos objetivos da UC (adequada, tolerável, inadequada) } \\
\hline Resultado: & \multicolumn{6}{|c|}{ sucesso, sucesso parcial, insucesso } \\
\hline Motivo: & \multicolumn{6}{|c|}{ opinião - parte aberta da pergunta } \\
\hline
\end{tabular}

Optou-se por essas diferentes possibilidades para um balanço entre a opinião direcionada por alternativas e a liberdade de expressão. A primeira, dada pelas perguntas fechadas, permite uma análise mais objetiva e direta das respostas. A segunda permite a livre classificação da pessoa questionada, o que 
possibilita verificar o seu grau de conhecimento sobre o objeto da pergunta (nos casos das atividades dos moradores e das ações de manejo e extensão), bem como sua percepção e opinião (no caso do motivo para justificar o resultado das ações de manejo e extensão).

Para compor o perfil da amostra, considerou-se como funcionário o pessoal com funções de chefia e coordenação, manejo, administração e serviços gerais ligados às instituições responsáveis pela administração das referidas unidades, inclusive co-gestores e parceiros envolvidos. A amostra, por parque, foi de um mínimo de cinco questionários ou de $20 \%$ do pessoal, em virtude da grande variação no número total de funcionários, independentemente do tamanho da unidade de conservação. Sempre que possível, optou-se por funcionários ligados a funções de manejo, devido à sua maior integração com as ações aplicadas nas localidades rurais. Os trabalhos de coleta de dados em campo foram realizados no ano de 2001, no período de 25 a 29 de março na Reserva Natural Salto Morato (PR), de 21 de abril a 02 de maio no Parque Estadual da Ilha do Cardoso (SP), de 04 de junho a 01 de julho no Parque Nacional do Jaú (AM), de 06 a 22 de agosto no Parque Nacional da Serra da Capivara (PI), de 28 de agosto a 13 de setembro no Parque Nacional Grande Sertão Veredas (MG) e no período de 09 a 27 de novembro no Parque Nacional Chapada dos Veadeiros (GO). Os questionários foram aplicados pela autora, que, previamente, sempre se identificou como estudante de conservação da natureza do curso de pósgraduação da Universidade Federal do Paraná, apresentou os objetivos da pesquisa, listou as unidades selecionadas e garantiu o sigilo sobre a autoria das informações repassadas. Durante as atividades de campo, também foram anotadas observações sobre cada localidade visitada, situações vivenciadas e comentários/relatos efetuados após a aplicação dos mesmos. Essas anotações visaram facilitar a memória do dia de trabalho, como um diário de campo, e também registrar questões e percepções importantes relativas ao tema estudado.

As respostas às perguntas fechadas foram estruturadas em tabelas e codificadas para fins de tabulação. As respostas numéricas, como idade e tempo de residência ou serviço, foram classificadas em intervalos e, do mesmo modo, organizadas em tabelas com códigos para a tabulação. Por fim, as respostas abertas foram listadas, organizadas em tabelas, codificadas e classificadas em grupos para reduzir o número de variáveis a serem analisadas e permitir a comparação entre as unidades. Os resultados dos questionários foram tabulados em programa clipper, desenvolvido pelo técnico Luís Alceu Paganotto, do Instituto Brasileiro de Geografia e Estatística (IBGE). As tabelas com os resultados foram transportadas para o programa Excel, do sistema Windows, para a contagem das respostas. Os resultados dos questionários foram, primeiro, analisados por unidade, depois em sua totalidade e por fim comparados entre si. As opiniões também foram analisadas considerando-se as informações bibliográficas e observações efetuadas pelos autores no decorrer do trabalho de campo.

\section{RESULTADOS E DISCUSSÃO}

Os números e percentuais dos questionários aplicados aos funcionários em cada unidade e o total para o conjunto estudado encontram-se na Tabela 2. Há discrepância de representatividade da amostra entre os parques estudados. A disponibilidade de pessoal para a entrevista e o baixo número de funcionários resultaram em valores elevados na RNSM e no PNJ. O contrário resultou em valores inferiores ou iguais ao número mínimo requerido (20\%), como no PEIC e no PNCV. Ressalta-se que, no PEIC, de um total de 54 pessoas no quadro funcional, 47 atuam em serviços gerais ou de manutenção ou são prestadores de serviços.

Os funcionários das unidades pesquisadas eram, em sua maioria, do sexo masculino $(81,4 \%)$ e metade tinha entre 31 e 40 anos (48,8\%). Grande parte respondia ou por funções de manejo (46,5\%), ou de chefia e coordenação de projetos $(41,9 \%)$, e desempenhava suas funções ou há mais de cinco anos $(46,5 \%)$, ou há menos de dois $(30,2 \%)$. Os resultados das seis unidades estudadas não apresentaram diferenças substanciais da sua análise conjunta, destacando-se, apenas, algumas especificidades relativas ao perfil ocupacional dos funcionários. Somente em três unidades (RNSM, PNSC e PNGSV), a metade ou a maioria dos funcionários responsabilizava-se por funções de manejo. Também nos parques nacionais do Jaú, Serra da Capivara e Grande Sertão Veredas, boa parte dos funcionários era ligada às instituições co-gestoras dos parques e não diretamente ao Instituto Brasileiro do Meio Ambiente e dos Recursos Naturais Renováveis (IBAMA), instituto por elas legalmente responsável. 
Tabela 2. Número de funcionários conforme suas funções desenvolvidas na unidade de conservação e número e percentual de questionários aplicados.

Table 2. Number of employees according to their function in parks and number and rate of applied questionnaires.

\begin{tabular}{lcccccc}
\hline Unidade de Conservação & $\begin{array}{c}\text { Chefes e } \\
\text { Coorde- } \\
\text { nadores }\end{array}$ & $\begin{array}{c}\text { Função de } \\
\text { Manejo }\end{array}$ & $\begin{array}{c}\text { Função } \\
\text { Administrativa e } \\
\text { Serv. Gerais }\end{array}$ & $\begin{array}{c}\text { Total } \\
\text { Funcio- } \\
\text { nários }\end{array}$ & $\begin{array}{c}\text { No } \\
\text { Quest. }\end{array}$ & $\begin{array}{c}\text { \%o } \\
\text { Quest. }\end{array}$ \\
\hline Reserva Natural Salto Morato & 3 & 3 & 1 & 7 & 6 & 85,7 \\
\hline Parque Estadual Ilha do Cardoso & 1 & 3 & 23 & 27 & 5 & 18,5 \\
\hline Parque Nacional do Jaú & 5 & 1 & 3 & 14 & 45 & 12 \\
\hline Parque Nacional da Serra da Capivara & 4 & 27 & -- & 14 & 7 \\
\hline Parque Nacional Grande Sertão Veredas & 4 & 10 & 6 & 26,7 & 50,0 \\
\hline Parque Nacional Chapada dos Veadeiros & 4 & 15 & $\mathbf{4 7}$ & $\mathbf{1 2 7}$ & $\mathbf{4 3}$ & 20,0 \\
\hline Total & $\mathbf{2 1}$ & $\mathbf{5 9}$ & $\mathbf{3 3 , 9}$ \\
\hline
\end{tabular}

\section{Reserva Natural Salto Morato}

A administração da reserva é responsabilidade da Fundação O Boticário de Proteção à Natureza (FBPN) e, desde 1996, desenvolve ação de extensão aos moradores da vila Morato, localizada no entorno da unidade. Essa ação visa implementar alternativa econômica (artesanato) para melhorar as condições sociais e fortalecer a organização dos moradores (FBPN, 2001) e reduzir a pressão sobre os recursos naturais, principalmente pela extração de palmito e caça. Conforme informações verbais do responsável pela Reserva (Caiut, 2001), também foram realizadas ações de educação ambiental nas escolas da região, principalmente na da vila, com a realização de curso para formação de guias-mirins. Outra ação importante é a contratação de mão-de-obra local para serviços de manejo na unidade, tanto em caráter permanente como temporário.

As atividades dos moradores do entorno da RNSM mais citadas pelos funcionários foram as extrativistas (corte de madeira, extração de palmito, caça) e agropecuárias. Suas opiniões sobre a adequação das atividades dos moradores aos objetivos da unidade foram equivalentes ao que designa a Lei Federal no 9.885/2000 (Brasil, 2000), que institui o Sistema Nacional de Unidades de Conservação da Natureza (SNUC), isto é, consideradas inadequadas para dentro de unidades de proteção integral. Para o entorno, a roça e criação de animais foram consideradas adequadas ou toleráveis, e a pesca e a extração de cipó, toleráveis. Ressalta-se que, tanto nessa unidade como nas demais, nem todos os funcionários citaram todas as atividades e, por isso, não são apresentados os referidos percentuais para essa questão.

Os funcionários citaram três tipos de ações (controle e pressão para inibir atividade; programa de artesanato; diálogo e articulação) para quatro diferentes atividades efetuadas pelos moradores (criação de gado, corte de madeira, extração de palmito, caça). Na opinião deles, todas essas ações obtiveram sucesso. Os principais motivos apontados para os resultados positivos são: 'melhora nas formas de sustento e trabalho' (30,4\% dos motivos), relacionada principalmente ao desenvolvimento do programa de artesanato; 'situação existente facilita o resultado' $(21,7 \%)$, para a inibição da entrada do gado na Reserva; 'medo da fiscalização' (17,4\%), para ações de controle desta última atividade e do extrativismo ilegal (palmito, madeira e caça); e 'abordagem adequada e clareza na comunicação' na aplicação das ações (17,4\%). Somente na opinião de um funcionário a implantação da unidade tem resultado parcial por 'falta de compreensão e consciência'.

\section{Parque Estadual da Ilha do Cardoso}

O Instituto Florestal de São Paulo é responsável pela administração do PEIC e, com o "Plano de manejo - Fase 1" (São Paulo, 1998), iniciou-se uma nova abordagem com os moradores do parque. Nesse processo, destacou-se a criação de um comitê de apoio à gestão da unidade, cuja principal função é controlar e regulamentar as atividades dessas comunidades residentes e dos serviços turísticos. Conforme informações verbais do responsável pela unidade (Campolin, 2001), em 1997 iniciou-se também o desenvolvimento de ações de educação ambiental e para melhoria dos serviços de turismo, com maior intensidade de trabalho na localidade de Marujá, que recebe maior número de visitantes.

As atividades dos moradores do PEIC mais citadas pelos funcionários foram as extrativistas 
(pesca, extração de molusco, caça, corte de madeira, extração de palmito, extração de samambaia e cipó, extração de calcário), a roça e a prestação de serviços turísticos, esta mais recente. Somente a pesca e a extração de molusco foram citadas para o entorno; as demais atividades foram citadas para dentro dos limites do parque. Ressalta-se que a maioria dos que responderam ao questionário considerou apenas a caça, a extração de palmito, as extrações de molusco e de calcário como inadequadas para dentro dos limites da unidade. As demais atividades desenvolvidas pelos moradores dentro dos limites do parque foram consideradas adequadas ou toleráveis pela maioria deles. Com exceção dos serviços turísticos, essas opiniões admitem o uso direto em unidade de conservação de proteção integral, o que demonstra falta de conhecimento ou orientação contrária à lei do SNUC. Não foram citadas opiniões sobre a adequação das atividades para o entorno.

Os funcionários citaram cinco tipos de ações (controle e pressão para inibir atividade; regulamentação e monitoramento; regulamentação de atividade ilegal na unidade; organização e educação ambiental; diálogo e articulação) para diferentes atividades efetuadas pelos moradores. Na opinião deles, a maioria delas obteve sucesso ou sucesso parcial. O sucesso parcial foi relacionado, principalmente, a ações de controle de atividades ilegais na unidade, de educação ambiental para pesca e de regulamentação do turismo. Já o sucesso foi sempre relacionado às ações de diálogo, que se referem à existência do conselho de apoio à gestão do parque, e à regulamentação da pesca e da extração de caranguejo ou moluscos. O principal motivo apontado para os resultados positivos no controle foi o medo da punição (20,8\% do total de motivos citados), e para os negativos, a falta de condições de trabalho $(20,8 \%)$. Para o sucesso das ações de diálogo e regulamentação citou-se, principalmente, a utilização de uma abordagem e comunicação adequadas $(33,3 \%)$. Também as condições sociais e ausência de alternativa econômica foram citadas como motivos para a dificuldade em alcançar o sucesso nas ações de controle e de educação ambiental para a pesca.

\section{Parque Nacional do Jaú}

O PNJ é administrado pelo IBAMA. Em 1995, a Fundação Vitória Amazônica (FVA) começou a implementação de projetos de desenvolvimento, integração e melhoria das condições sociais das comunidades do PNJ e entorno, com ações de extensão direcionadas, principalmente, à melhoria das condições de educação, saúde e comunicação dos moradores da unidade (FVA, 1998). Em 1994, foi iniciado o projeto Fibrarte, que incentiva a organização social, desenvolve a produção de artesanato e realiza educação ambiental para artesãos de Novo Airão (núcleo urbano mais próximo) e moradores do parque. Ressalta-se que essa ação necessita de fibras e produtos florestais, que também são extraídos no PNJ. Em 1998, também se efetuou curso para formação de agentes ambientais voluntários, para integrar os moradores ao manejo da unidade por meio dos serviços de proteção (Pinheiro, 1999).

As atividades dos moradores do parque e entorno mais citadas pelos funcionários foram as extrativistas (caça, pesca, captura de quelônios, coleta de peixes ornamentais, coleta de cipó, corte de madeira, extração de seiva) e a roça. Apenas a extração de cipó foi citada para o entorno; as demais foram citadas para dentro dos limites do parque. A grande maioria dos funcionários que opinou sobre a adequação das atividades dos moradores considerou a roça como adequada ou tolerável para dentro dos limites do parque. Boa parte deles assim considerou o extrativismo vegetal e alguns, também a caça. Essas opiniões admitem o uso direto em unidade de conservação de proteção integral, o que demonstra falta de conhecimento ou orientação contrária à lei do SNUC. Metade dos funcionários considerou a caça, a pesca, a captura de quelônios e a coleta de peixes ornamentais inadequadas para dentro dos limites do parque. Não foram citadas opiniões sobre a adequação de atividades para o entorno. Isso pode ser em virtude das ações serem voltadas principalmente aos moradores da unidade e/ou pela baixa relação entre o número de funcionários e a área do parque.

Os funcionários citaram cinco tipos de ações (controle e pressão para inibir atividade; regulamentação de atividade ilegal na unidade; organização e educação ambiental; diálogo e articulação; ações de extensão) para as diferentes atividades efetuadas pelos moradores. As poucas indicações de sucesso foram relacionadas às ações de regulamentação das atividades ilegais para a categoria da unidade e justificadas pelo uso de 'abordagem adequada' (6,1\% do total de motivos) e de 'técnicas adequadas' $(4,5 \%)$. A maioria das opiniões indicou sucesso parcial e foi relacionada, principalmente, a ações de controle, de educação ambiental e de regulamentação de atividades inadequadas aos objetivos da categoria parque. Algumas opiniões indicaram insucesso e foram relacionadas às ações de controle, de educação ambiental e organização e também de regulamentação das atividades ilegais. A maior parte dos 
resultados negativos foram justificados pela 'falta de condições de trabalho' na unidade (48,5\% do total de motivos), 'falta de conhecimento com trabalho comunitário' (9,1\%) e 'abordagem e técnica inadequadas' $(9,1 \%)$.

\section{Parque Nacional da Serra da Capivara}

Desde sua criação, o IBAMA e a Fundação Museu do Homem Americano (FUMDHAM) efetuam a gestão conjunta do PNSC. Em 1989, a FUMDHAM iniciou um programa de integração da população do entorno para reduzir os impactos das formas de uso da terra e fazer a população local compreender que o parque lhe seria benéfico (Guidon, 2001), cujos principais objetivos são o desenvolvimento alternativo e a efetiva proteção da unidade (Guidon, 1996). Conforme Guidon (2001), foram implantados cinco Núcleos de Apoio à Comunidade (NACs) até 2001, com serviços e infraestrutura na área de educação e saúde. Também foram realizadas oficinas para capacitação de pessoal local para, principalmente, o artesanato em cerâmica e a atuação em serviços de manejo na unidade, como proteção, prevenção de incêndios, guiagem, auxílio à pesquisa, intervenção em sítios arqueológicos e manutenção. Em 2001, a FUMDHAM contratou 92 pessoas da região para serviços no parque.

As atividades dos moradores do PNSC e entorno mais citadas pelos funcionários foram as agropecuárias (roça e criação de gado e outros animais) e as extrativistas (caça, madeira, calcário e seiva), tanto para dentro do parque como para seu entorno. A maior parte dos funcionários que opinou sobre a adequação das atividades considerou a roça e o extrativismo desenvolvidos pelos moradores dentro dos limites da unidade como inadequadas. Alguns poucos opinaram que a roça, a madeira para lenha e a extração de calcário em rocha poderiam ser toleráveis dentro da unidade, o que discorda da lei do SNUC. Alguns deles apenas consideraram essas atividades como adequadas ou toleráveis para o entorno, sendo que muitos as consideraram inadequadas mesmo para essa localização. A caça foi sempre considerada inadequada.

Os funcionários citaram seis tipos de ações (controle e pressão para inibir atividade; regulamentação e monitoramento no entorno; regulamentação de atividade ilegal na unidade; organização e educação ambiental; diálogo e articulação; implantação da unidade, que inclui ações de uso público e proteção com contratação de pessoal local, principalmente) para as diferentes atividades efetuadas pelos moradores. A maioria das opiniões foi que essas ações obtiveram sucesso ou sucesso parcial. Os resultados de sucesso foram mais citados para as ações de controle, educação ambiental e implementação do uso público. O sucesso parcial foi relacionado, principalmente, com ações de controle da caça, regulamentação de atividades no entorno e controle de atividades ilegais dentro do parque, como a roça, enquanto a indenização não ocorre. A maior parte dos motivos para os resultados de sucesso foi relacionada com o 'medo da fiscalização' (21,5\% do total de motivos) e com a utilização de 'abordagem adequada' (16,5\%). Para justificar resultados negativos, os motivos mais citados foram que 'não há alternativa econômica' ou 'as condições sociais não permitem mudança' das atividades efetuadas pelos moradores (19\%), uso de 'abordagem inadequada' $(8,9 \%)$, o 'problema está fora da abrangência do parque' $(6,3 \%)$, como também 'falta de condições de trabalho' na unidade $(6,3 \%)$.

\section{Parque Nacional Grande Sertão Veredas}

A Fundação Pró-Natureza (FUNATURA) trabalha em parceria com o IBAMA desde a época de criação do PNGSV. Segundo Ferreira (1996), em 1991 iniciou-se o desenvolvimento do Programa Grande Sertão Veredas, com ações de conscientização ambiental nas comunidades do parque e região, nos temas: agricultura e parque (produtividade, conservação, difusão de técnicas simples e alternativas), saúde e parque (planejamento familiar, higiene, lixo, alimentação, doenças, plantas medicinais, tratamentos populares), educação informal e parque (atividades em escolas rurais e de áreas próximas, recreação e comemorações ambientais), incentivo à participação e fortalecimento das comunidades locais (reuniões comunitárias informais). Ressalta-se o uso da visita social para contatos informais e da atuação técnica para a formação de massa crítica, sem a indução de atitudes (FUNATURA, 1995). Em 1997, a FUNATURA iniciou negociação com o Instituto Nacional de Colonização e Reforma Agrária (INCRA) para aquisição de terras ao assentamento dos posseiros do parque (Espírito Santo, 2001), cujo processo de relocação encontrava-se em discussão durante a aplicação dos questionários desta pesquisa.

As atividades dos moradores do PNGSV e entorno mais citadas pelos funcionários da unidade foram as agropecuárias com utilização do fogo (roça, criação de gado, monocultura mecanizada) e extrativistas (caça, tráfico de aves, coleta de peixes ornamentais, produção de carvão vegetal, corte de 
madeira, coleta de frutos e sementes). A pesca foi apenas citada para o entorno. Todos os funcionários que opinaram sobre a adequação das atividades dos moradores consideraram como inadequadas a agropecuária e o extrativismo desenvolvidos dentro dos limites do parque. Para o entorno, alguns poucos consideraram as atividades de roça, criação, pesca e coleta de frutos e sementes como adequadas, e outros as de roça, criação, monocultura e produção vegetal como toleráveis.

Os funcionários citaram cinco tipos de ações (controle e pressão para inibir atividade; regulamentação de atividade ilegal na unidade; organização e educação ambiental; diálogo e articulação; implantação da unidade, que inclui ações de uso público e proteção com contratação de pessoal local) para as diferentes atividades efetuadas pelos moradores. Na opinião deles, a maioria das ações obteve sucesso, algumas sucesso parcial e poucas, insucesso. Os resultados de sucesso foram mais citados para as ações de controle, articulação e negociação, organização e educação ambiental e implementação do uso público na unidade. $\mathrm{O}$ sucesso parcial e o insucesso foram relacionados principalmente com ações de controle da criação de gado e de regulamentação de atividades ilegais dentro do parque, enquanto não ocorre a indenização. A maior parte dos motivos para o alcance dos resultados positivos relaciona-se com o 'medo da fiscalização' (29,5\% do total de motivos) e com a utilização de 'abordagem adequada' (18\%). Para justificar resultados negativos, os motivos mais citados foram a 'falta de condições de trabalho' na unidade (16,4\%), a 'ação (indenização) não é prioridade' para o parque $(13,1 \%)$, o uso de 'técnica e manejo inadequados' (8,2\%), que 'não há alternativa econômica' ou 'as condições sociais não permitem mudança' das atividades efetuadas pelos moradores $(4,9 \%)$ e que o 'problema está fora da abrangência de competência do parque' $(4,9 \%)$.

\section{Parque Nacional da Chapada dos Veadeiros}

O Projeto Veadeiros foi uma das iniciativas desenvolvidas na região do PNCV, em que o WWFBrasil coordenou ações para integrar conservação e desenvolvimento no Cerrado. Entre elas, destacam-se a capacitação de moradores da vila de São Jorge (entorno do parque) para serviços turísticos, principalmente guiagem, e o apoio à criação de áreas privadas para proteção à natureza. Inicialmente, o projeto também visava organizar e implementar o extrativismo de flores secas, além de outra alternativa econômica viável e de baixo impacto, a ser identificada (WWF, 1995). Apesar de seu pioneirismo e grande importância regional, essas atividades não lograram êxito pela falta de produção, de interesse da população e de mercado para seus produtos, além das associações fracas, desarticuladas e criadas por organismo superior (Valarelli e Zanetti, 1998).

As atividades dos moradores do entorno do PNCV mais citadas pelos funcionários da unidade foram o garimpo, as atividades agropecuárias com a utilização do fogo, a coleta de flores secas, os serviços turísticos e o desenvolvimento da economia regional. A maioria dos funcionários que opinou sobre a adequação das atividades dos moradores considerou apenas os serviços turísticos e o conseqüente desenvolvimento trazido pelo parque como adequados para a unidade, e um deles considerou tolerável a roça e a criação de gado para o entorno. As demais atividades foram consideradas inadequadas para dentro dos limites do parque, e algumas delas também para o entorno.

Os funcionários citaram três tipos de ações (educação ambiental e orientação para o uso do fogo; implantação da unidade, que inclui ações de uso público com pessoal local, principalmente; ação de extensão para apoio à organização do turismo no entorno) para as diferentes atividades efetuadas pelos moradores. Na opinião deles, todas ações obtiveram sucesso ou sucesso parcial. O 'medo do controle' foi relacionado ao sucesso da substituição do garimpo pelas atividades turísticas; a 'abordagem adequada', ao sucesso parcial do desenvolvimento do uso público no parque e ao incentivo para serviços turísticos no entorno; e o 'uso de técnicas e manejo adequados', à implantação do uso público no parque. Os motivos para resultados positivos foram relacionados ao uso de 'abordagem adequada' (35,3\% do total de motivos) e de 'técnicas e manejo adequados' (23,5\%), como também ao 'medo da fiscalização' (5,9\%). A dificuldade para alcançar o sucesso foi relacionada às 'condições culturais que não possibilitam mudanças' (11,8\%), a 'problemas fora da abrangência da competência do parque', ao 'uso de técnicas e manejo inadequados', à utilização de 'abordagem inadequada' $(5,9 \%)$ e à 'falta de conhecimento e compreensão' $(5,9 \%)$.

\section{Análise global e comparações}

Concordando com o exposto por Jorge-Pádua (1997) e Milano (1997), todas as unidades de conservação públicas tiveram e ainda têm problemas em seus processos de regularização fundiária. $\mathrm{O}$ 
PNCV encontrava-se sem moradores em seu interior e o PNSC já realizou a relocação da grande maioria de seus moradores. No PNGSV, a relocação dos posseiros que ainda viviam no parque na época dos trabalhos de campo dessa pesquisa estavam em processo de reassentamento, orientado pela instituição cogestora da unidade. Já o PEIC e o PNJ efetuam ações de manejo no sentido de manter e melhor estruturar a vida dos moradores interiores.

Em todas as unidades as ações de físcalização foram intensivas e algumas ainda necessitam mantê-las com o mesmo grau de atuação para controlar as atividades existentes, principalmente o extrativismo, comum em todas as regiões. Ações de controle causam animosidades entre as comunidades e as administrações das unidades, entretanto percebeu-se que há fatores que podem minimizá-las. No PNGSV, essas ações foram acompanhadas de visitas e reuniões, realizadas por pessoal da co-gestora, a fim de orientar e informar os moradores sobre a necessidade e a importância da unidade de conservação. Com isso, apesar do desconforto gerado, percebeu-se uma melhor compreensão, e, adicionada à oferta de trabalho pela unidade, uma mais fácil aceitação das ações de controle por parte dos moradores, como no PNSC (Hauff, 2004).

O número de funcionários nas unidades estudadas foi, em geral, reduzido, o que corrobora, mais uma vez as afirmações de Jorge-Pádua (1997), exceção feita ao setor administrativo e de manutenção do PEIC. Destaca-se que, durante a fase de campo desta pesquisa, o PNJ, segundo maior parque do país, possuía em seu quadro apenas um funcionário do IBAMA.

Quanto às ações de extensão, no PNGSV, no PNJ e no PEIC, mesmo com orientações diferentes, fundamentaram-se no diálogo para orientar a prática da roça e as formas de uso dos recursos naturais pelos moradores dentro das unidades. No primeiro, o objetivo principal era reduzir os impactos da presença de moradores, enquanto aguardava-se o processo de relocação. Nos outros dois, visava melhorar a situação de vida dos moradores e sua manutenção dentro das unidades, por meio da regulamentação e controle de suas atividades, o que é contrário aos preceitos legais da categoria parque. Nos PNCV e PNGSV houve intenções de desenvolver atividades extrativistas sustentáveis no entorno das unidades, as quais não conseguiram ser implementadas por problemas de mercado, bem como de desarticulação e desinteresse por parte da população.

Schaik e Rijksen (2002) afirmam que esse desinteresse é uma das dificuldades na formulação dos ICPDs, por eles assumirem uma concepção de ajuda à população quando esta nem sempre os deseja ou os considera bem-vindos. Os autores também apontam que esses projetos muitas vezes assumem mais o uso sustentável dos recursos naturais em parques que sua proteção. Isso pode ser relacionado às ações de extensão do PNJ, como o projeto Fibrarte (FVA, 1999), que mantêm e acabam incentivando a exploração de recursos dentro do Parque, o que é ilegal para essa categoria de manejo. Os mesmos autores ainda afirmam que esse tipo de ação encoraja outras pessoas a entrarem nas áreas protegidas, bem como discorrem sobre o apelo dado ao termo "usos tradicionais", que geralmente refletem situações de baixa densidade demográfica e inexistência de exploração comercial. Para Homma (2000), o extrativismo, que historicamente tem contribuído com a pauperização, só se mantém em pequenos mercados, já que sua ampliação é inviável para a sustentabilidade dos recursos e, por isso, o cultivo é inevitável, quando tecnologicamente possível. Ressalta-se que Ayres et al. (1996), ao relatarem o manejo sustentável de recursos naturais em unidades de conservação, afirmam que a caça e o corte seletivo de espécies vegetais modificam o tamanho e distribuição das populações silvestres, fato agravado quando há comercialização e pressão do mercado. Mesmo assim, Brandon (2002) afirma que projetos dessa natureza, em áreas remotas e fundamentados em pesquisa e treinamento de pequena escala, podem estabilizar usos e ameaças e constituir apoio à conservação de áreas protegidas.

O PNGSV, o PNSC e o PNJ, com diferentes dimensões, desenvolveram ainda ações voltadas a melhorias sociais. O primeiro fundamentou-se na transferência de informações e atendimento domiciliar para questões de saúde, sem estabelecer esses serviços dentro da unidade. No PNJ, as melhorias nos serviços de saúde e educação se deram dentro da unidade. Já o PNSC implementou os núcleos de apoio à comunidade no entorno da unidade, com infra-estrutura e serviços de educação e saúde, principalmente. Nesse caso, a continuidade e qualidade das ações ficaram comprometidas depois da transferência da administração dos núcleos ao setor competente da administração pública.

O PNSC e, principalmente, o PNCV, implementaram o uso público na unidade e realizaram cursos para a formação de condutores de visitantes como forma de ofertar oportunidades de serviços locais (WWF, 2001). Essas foram atividades bem recebidas pelos moradores do entorno, mas 
apresentaram alguns problemas de execução relativos, principalmente, ao aprimoramento e qualificação profissional das pessoas que as exercem, já que sua conduta influencia o manejo da unidade.

Na RNSM, no PNGSV e no PNSC, as políticas internas de treinamento e contratação de pessoal local para trabalho nas unidades foram ações de aproximação e valorização dos moradores locais. Conforme Hauff (2004), essas políticas facilitaram o diálogo e reduziram a visão negativa dos moradores sobre as restrições impostas pela existência da unidade, como normalmente acontece onde a proteção e o controle sobre o uso dos recursos naturais é ausente (Oldfield, 1988). Essa maior aceitação foi relacionada, principalmente, à carência de oportunidades de trabalho com rendimento adequado, lícito ou regular para essas populações rurais.

Nos questionários, como mostra a Figura 2, as atividades dos moradores mais citadas pelos funcionários das unidades foram as agropecuárias (roça e criação de gado) e extrativistas (caça, corte de madeira, pesca, extração de palmito e outros vegetais). Houve mais citações de atividades para dentro das unidades que para o entorno, o que deve estar relacionado ao fato de haver maior número e intensidade de ações nelas do que no entorno, em vista da pouca estrutura de trabalho e a existência de moradores no interior de quatro parques (PEIC, PNJ, PNSC, PNGSV). Como demonstra a Figura 3, os funcionários consideraram a caça, a criação de animais, a extração de palmito e de carvão vegetal como atividades inadequadas para dentro dos limites das unidades. Contudo, entre os que opinaram sobre a adequação das atividades dos moradores, destaca-se que houve os que consideraram adequado ou tolerável, para dentro dos limites das unidades, a prática da roça, a extração de madeira, a extração de vegetais, exceto o palmito, e a pesca.

Parte dos funcionários admitiu o uso direto em unidades de conservação de proteção integral, o que demonstra falta de conhecimento ou discordância e orientação contrária à lei do SNUC. Essas opiniões, certamente, devem se refletir na execução de suas atividades e podem gerar conflitos, tanto no cumprimento dos objetivos e funções de conservação da unidade como na comunicação e confiança entre as administrações e as comunidades, pois as ações são contrárias às obrigações legais e, conseqüentemente, não poderão ser mantidas. Em algumas respostas de funcionários ao questionário aplicado, evidenciam-se dificuldades no trabalho com comunidades, além da falta de estrutura condizente para a realização do manejo adequado das unidades e do conhecimento e concepção incorretos sobre a categoria parque. Isso reforça as observações sobre as carências de treinamento e programas de capacitação de administradores de unidades de conservação para esse tipo de trabalho (Oldfield, 1988; Costa Rica, 1990; Milano, 1991; Barborak, 1997).

Além disso, a concepção inadequada de ações de extensão afeta sua implementação e resultados. Isso encontra respaldo no próprio relato do "Plano de manejo - Fase 2" (São Paulo, 2001), que avalia que o controle e regulamentação de algumas atividades previstas na fase 1 do plano de manejo foram, em alguns momentos, prejudicados pela ausência de amparo legal. Violar preceitos legais implica realizar promessas que não poderão ser cumpridas, e, dessa forma, o trabalho da unidade e, conseqüentemente, dos funcionários, poderá cair em descrédito, como exposto por Moore (1993), Lewis (1993), Mackinnon (1993), Dourojeanni (1997) e Wells et al. (1992). Hauff (2004) também discute que a manutenção de pessoas dentro das unidades de conservação de proteção integral, além de ser contrário ao SNUC e trazer prejuízos à conservação da natureza, objetivo maior das unidades, implica prejuízos aos próprios moradores, pois todas as suas atividades sofrem fortes restrições e regulamentações, seja para moradia, seja para produção.

No total, os funcionários citaram sete tipos de ações para as diferentes atividades efetuadas pela comunidade: 1) proibição, controle e pressão para inibir atividade; 2) regulamentação e monitoramento de atividades no entorno; 3) regulamentação de atividade ilegal na unidade; 4) educação ambiental, orientação e organização; 5) diálogo, articulação e negociação; 6) ação de extensão; e 7) implantação da unidade (como uso público, proteção e outras funções).

As ações de proibição, controle e pressão para inibir atividade dos moradores foram as mais citadas (70 citações) pelos funcionários e apenas não foram citadas para o PNCV, embora se tenha observado em campo que ela é realizada, mas não diretamente relacionada aos moradores. Em todas as cinco unidades, os funcionários avaliaram os seus resultados como de sucesso e/ou sucesso parcial. Seus resultados negativos foram, na maioria dos casos, relacionados à falta de condições de trabalho na unidade. 
Figura 2. Percentual das atividades dos moradores citadas pelos funcionários, conforme sua localização em relação às unidades de conservação.

Figure 2. Percentage of production activities carried out by local communities, inside and around parks, according to opinions of parks' personnel.

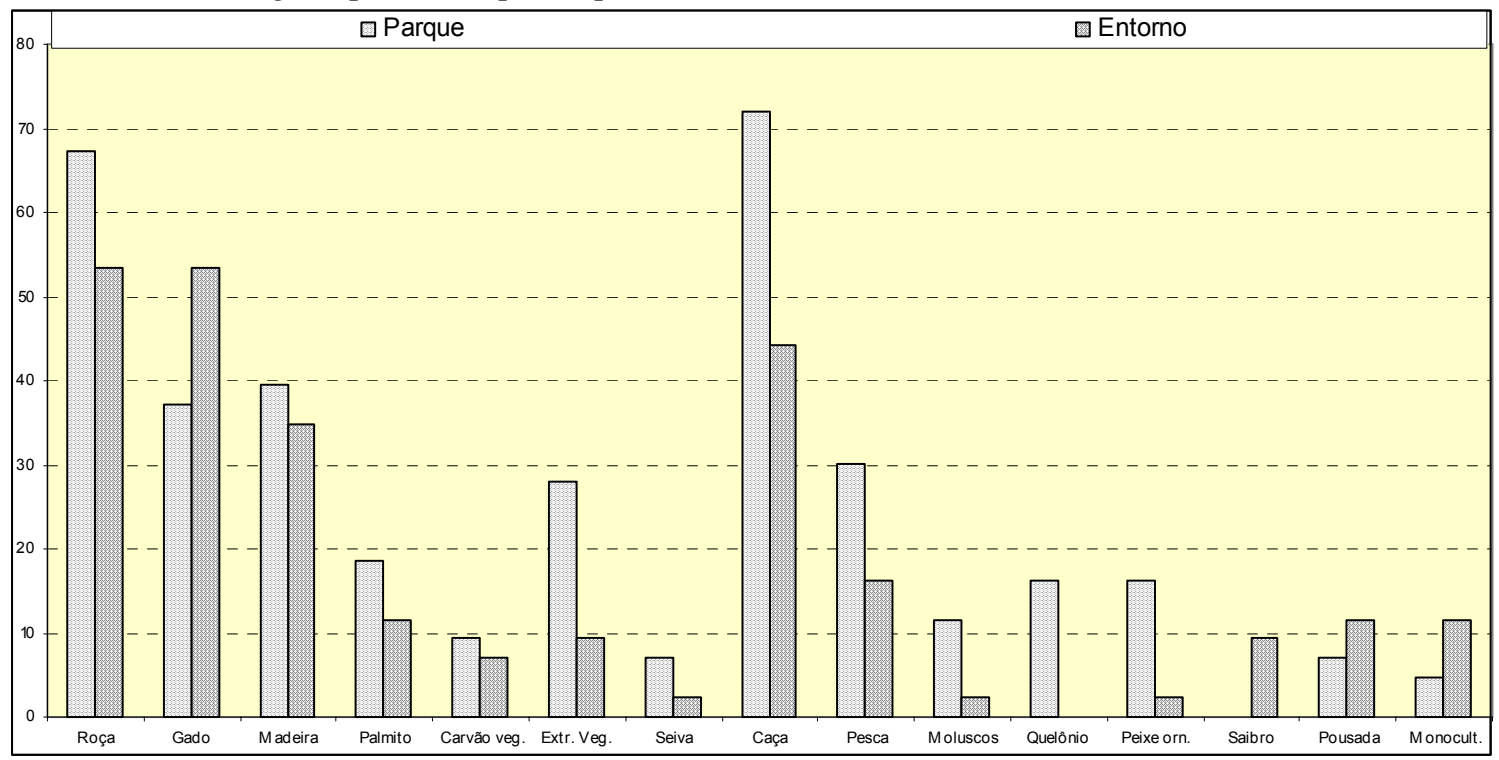

Figura 3. Percentual das opiniões dos funcionários sobre a adequação das atividades efetuadas pelos moradores, no entorno (E) e nos limites (P) da unidade de conservação, em relação sua categoria de manejo.

Figure 3. Percentage of opinions of parks' personnel about adequacy of production activities carried out by local communities, inside and in the surroundings of parks, according to management category of the protected area.

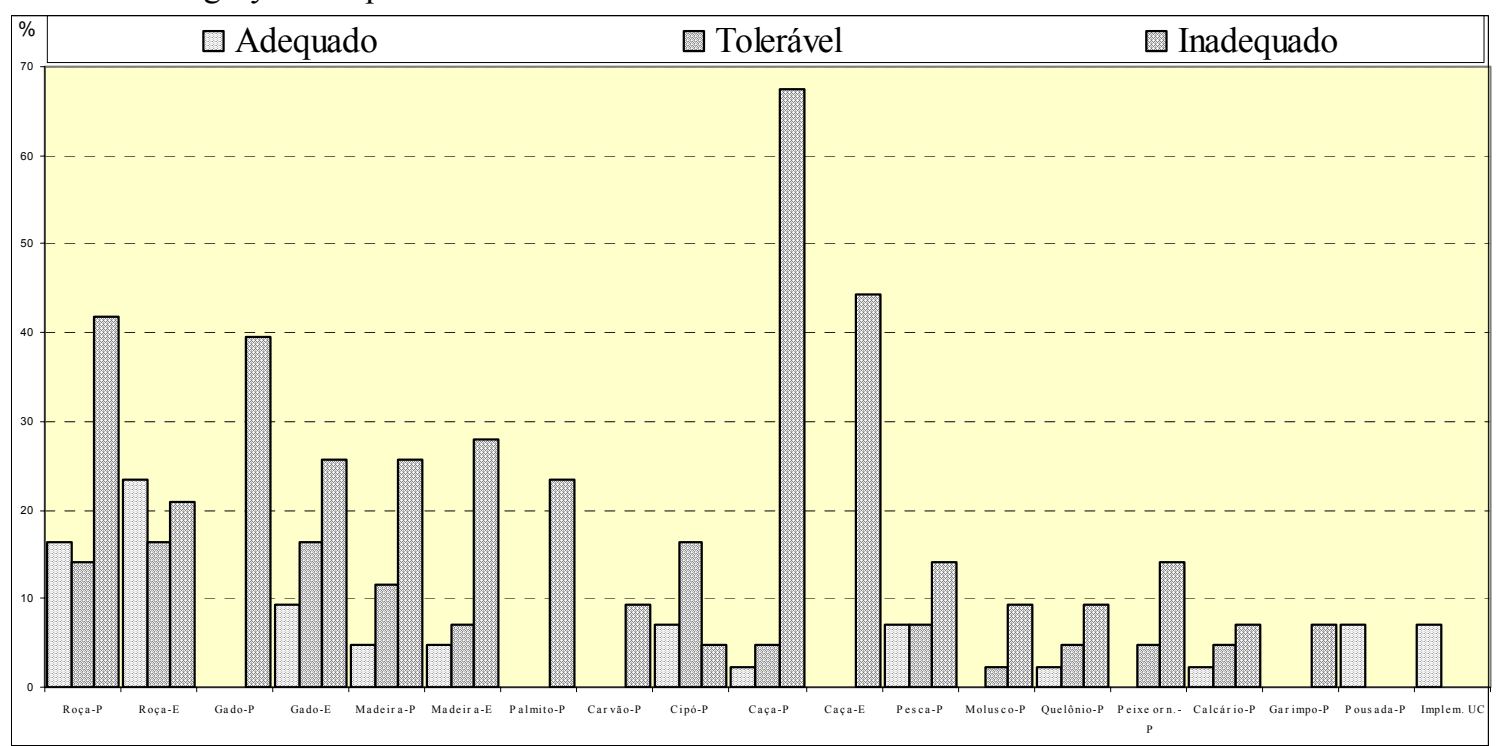

As ações de educação ambiental, orientação e organização também foram citadas em cinco unidades (PEIC, PNJ, PNSC, PNGSV e PNCV), entretanto com número de citações menor (25) que a metade do anterior. Somente no PNJ os resultados dessas ações foram avaliados predominantemente como insucesso, e no PNGSV todas as opiniões indicaram resultado de sucesso. No PNSC, as opiniões se 
dividiram entre sucesso e sucesso parcial; no PNCV e PEIC houve apenas uma citação para cada um desses resultados.

As ações de diálogo, articulação e negociação foram citadas para cinco unidades (RNSM, PEIC, PNJ, PNCV e PNGSV), mas principalmente para o PEIC (10 das 15 citações), onde estão ligadas à atuação do comitê de apoio à gestão do parque e todos os funcionários avaliam seus resultados como de sucesso. As ações de extensão, específicas para cada unidade, foram citadas para quatro unidades (RNSM, PEIC, PNJ e PNCV), mas com predominância na RNSM (10 das 16 citações), cujos resultados também foram avaliados apenas como de sucesso.

As ações de regulamentação de atividade ilegal à unidade foram citadas em todos os parques com moradores em seu interior (PEIC, PNJ, PNSC e PNGSV). Foi o segundo tipo de atividade mais citado (35 citações) e, em todas as unidades, predominou a opinião de resultado parcial. As ações de regulamentação e monitoramento de atividades no entorno somente foram citadas no PNSC (5 citações), que possui poucos moradores em seu interior e cujos resultados ficaram divididos entre sucesso e sucesso parcial, com uma indicação de insucesso.

As ações relativas à implantação da unidade foram citadas para o PNSC, PNCV e PNGSV, sendo que nas primeiras predominou a opinião de resultado de sucesso (4 para cada uma delas, de um total de 9 citações) e apenas no último houve duas opiniões de insucesso para uma de sucesso. Essas ações - relativas à implementação das funções de proteção, manejo de recursos, administração e manutenção, pesquisa e, principalmente, de uso público da unidade - facilitaram a aceitação de sua existência por parte dos moradores (Hauff, 2004), por oferecerem oportunidades de trabalho lícito e melhores perspectivas de renda e segurança.

A Figura 4 apresenta os motivos citados pelos funcionários das unidades de conservação para o resultado das ações de manejo e extensão efetuadas nas localidades rurais. Quando considerados os resultados negativos do sucesso parcial e do insucesso dessas ações, a maioria dos motivos foi relacionada à 'falta de condições de trabalho' (principalmente no PNJ, no PEIC e no PNGSV). Também foi citado que as 'condições socioeconômicas não permitem o sucesso' (PNSC e PEIC), que houve 'abordagem e comunicação inadequada' ou 'falta de clareza' (PNJ e PNSC) ou que a 'ação ou técnica é inadequada' (PNJ e PNGSV), além de o 'problema estar fora da abrangência da ação' da administração da unidade (PNSC e PNGSV). Para justificar o sucesso, a maior parte dos motivos citados foram o 'medo da fiscalização e punição' (PNGSV, PNSC, PEIC e RNSM), a 'abordagem e comunicação adequadas' (PNCV, PEIC, PNGSV, RNSM e PNSC), a 'ação ou técnica adequadas' (PNCV, PNSC e PNJ), a 'situação existente facilita o resultado' (RNSM, PEIC e PNSC), além da ação ter melhorado as 'formas de sustento e trabalho' (RNSM) ou a 'atividade dos moradores ser considerada de baixo impacto' (PEIC).

Figura 4. Percentual dos motivos citados pelos funcionários das unidades de conservação para o resultado das ações de manejo e extensão efetuadas nas localidades rurais.

Figure 4. Percentage of reasons cited by the parks' personnel, as regards the results of the management actions developed in the local communities.

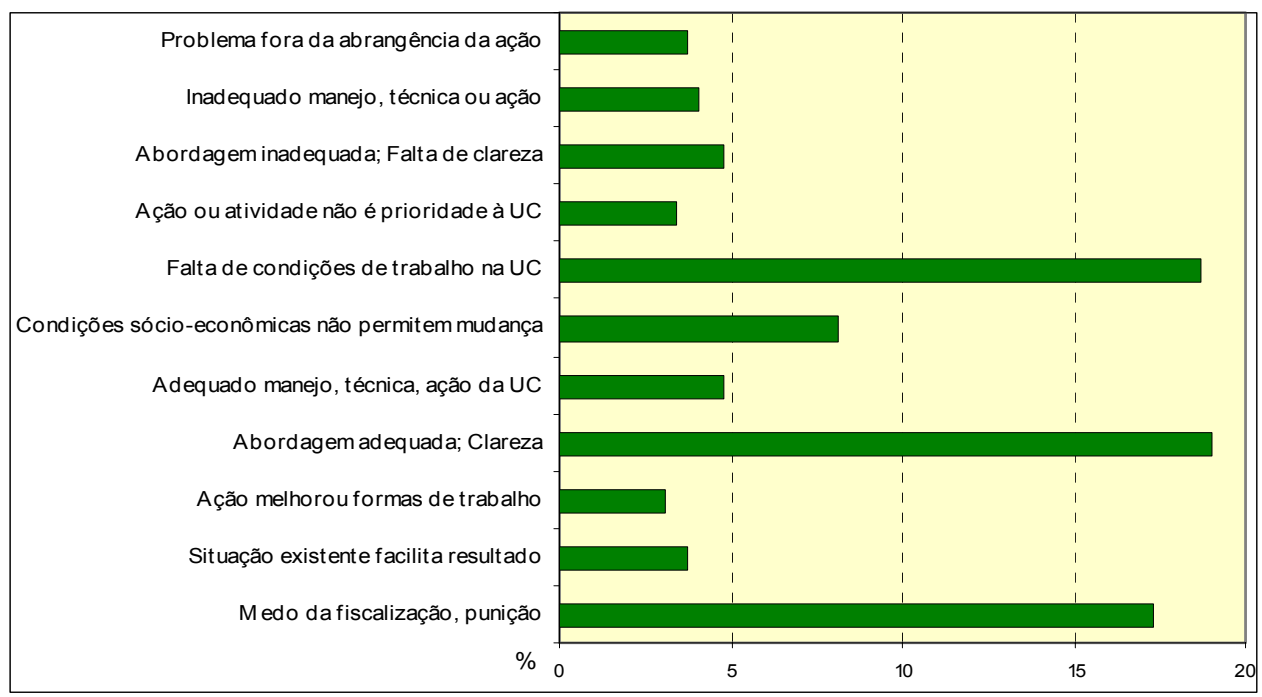

FLORESTA, Curitiba, PR, v. 35, n. 2, mai./ago. 2005 


\section{CONSIDERAÇÕES FINAIS E RECOMENDAÇÕES}

As atividades dos moradores mais citadas pelos funcionários das unidades foram as agropecuárias e extrativistas. Segundo eles, essas atividades são, geralmente, praticadas de modo ilegal, irregular ou por meio de práticas primitivas. A maioria das ações de extensão foi relativa a alternativas econômicas e de melhorias em serviços sociais, educação e saúde.

As ações de manejo e extensão e as de controle e fiscalização foram as que obtiveram maior número de citações e foram citadas para cinco das seis unidades de conservação estudadas, como também apresentaram maior resultado de sucesso, conforme a opinião de seus funcionários.

As ações de regulamentação de atividade ilegal à unidade foram o segundo tipo de atividade mais citada e presente para todos os parques com moradores em seu interior. Contudo, em todas as unidades predominou a opinião de resultado de sucesso parcial.

As ações de educação ambiental, orientação e organização foram o terceiro tipo de ação mais citado, aparecendo em cinco das seis unidades, e apresentaram resultado variável, conforme a unidade onde foram desenvolvidas.

Outros tipos de ações avaliadas com resultados predominantemente de sucesso foram relativos à ação de extensão e a processos de diálogo, articulação e negociação. A primeira foi relativa ao programa de artesanato na Reserva Natural Salto Morato, e a segunda à atuação do comitê de apoio à gestão do Parque Estadual da Ilha do Cardoso.

Os resultados positivos das ações de manejo e extensão foram relacionados, principalmente, ao medo da fiscalização e punição, seguido da utilização de abordagem e comunicação adequadas.

Os resultados negativos das ações de manejo e extensão foram relacionados, predominantemente, à falta de condições de trabalho na unidade, como também a condições socioeconômicas que não permitem modificar as atividades dos moradores, ao uso de abordagem e comunicação inadequada ou à falta de clareza.

A maioria das unidades estudadas apresentou reduzido quadro funcional, em vista das necessidades ao seu adequado manejo. As opiniões de alguns funcionários também demonstraram conhecimento ou concepções inadequados sobre a categoria de manejo parque, o que geralmente foi mais evidente nas unidades que implementam ações de extensão visando manter os moradores em seu interior, como o Parque Estadual da Ilha do Cardoso e o Parque Nacional do Jaú.

Considerando-se os resultados e conclusões deste estudo, recomenda-se que:

- as administrações das unidades de conservação de proteção integral privilegiem, sempre que possível, a conduta de treinamento e contratação de pessoal local para ações de manejo da unidade;

- as ações de extensão sejam implementadas por meio de abordagem clara, informativa e realista e sejam orientadas pelos objetivos de criação e manejo da unidade, bem como para o controle sobre as atividades que causem impactos ao meio natural;

- os funcionários dos parques devem ser adequadamente capacitados para compreender o seu papel e a função das unidades de proteção integral;

- os funcionários das unidades, sempre que possível e necessário, devem ser também treinados para o trabalho com comunidades;

- conforme determina a legislação, as ações de extensão e os trabalhos de co-gestão devem ser concordantes com os preceitos da categoria de manejo da unidade de conservação.

\section{AGRADECIMENTOS}

Os autores agradecem à Ana Lúcia Aurélio e Ana Carolina Freire, e ao CNPq, ao Programa Natureza e Sociedade (WWF/Brasil e USAID) e à Fundação O Boticário de Proteção à Natureza (FBPN), pelo apoio.

\section{REFERÊNCIAS}

AYRES, M. J.; LIMA-AYRES, D. de M.; ALBERNAZ, A. L.; ALVES, A. R.; MOURA, E.; QUEIROZ. H.; SANTOS, P.; BARTHEM, R. B.; SILVEIRA, R. da. Mamirauá um novo modelo de estação ecológica. Ciência Hoje, Rio de Janeiro, v.20, n.118, p.24-33, mar., 1996. 
BARBORAK, J. R. Mitos e Realidade da Concepção atual de áreas protegidas na América Latina. In: CONGRESSO BRASILEIRO DE UNIDADES DE CONSERVAÇÃO, Anais... Curitiba: IAP, 1997, v.1, p.39-47.

BRANDON, K. Colocando os parques certos nos lugares corretos. In: TERBORGH, J.; SCHAIK, C. VAN.; DAVENPORT, L.; RAO, M. Tornando os parques eficientes. Estratégias para a conservação da natureza nos trópicos. Curitiba: UFPR, 2002. p.inf.

BRASIL, Lei Federal no 9.885 de 18 de julho de 2000. Institui o Sistema Nacional de Unidades de Conservação da Natureza - SNUC. Diário Oficial da República Federativa do Brasil, Brasília, 19 de julho de 2000 .

CAIUT, J. A. Entrevista concedida à Shirley Noely Hauff. Guaraqueçaba, 26 mar. 2001.

CAMPOLIN, M. B. Entrevista concedida à Shirley Noely Hauff. Cananéia, 25 abr. 2001.

COSTA RICA. Servicio de Parques Nacionales. Informe del taller internacional sobre areas silvestres protegidas y comunidades locales. Reserva Monte Verde: Projecto FAO/PNUMA sobre Manejo de Áreas Silvestres, Áreas Protegidas y Vida Silvestre en América Latina y el Caribe/ Res Latinoamericana de Cooperación Técnica en Parques Nacionales, otras Área Protegidas, Flores y Fauna Silvestres, 1990. $34 \mathrm{p}$.

DOUROJEANNI, M. J. Areas protegida: problemas atiguos y nuevos, nuevos rumbos. In: Congresso Brasileiro de Unidades de Conservação, Anais.... Curitiba: IAP, 1997.v.1, p.69-109.

ESPÍRITO SANTO, C. V. Entrevista concedida à Shirley Noely Hauff. Chapada Gaúcha, 5 set. 2001.

FUNDAÇÃO O BOTICÁRIO DE PROTEÇÃO À NATUREZA. Resumo histórico do artesanato no Morato. Curitiba: FBPN. 2001. 2p. mimeografado.

FERREIRA, L. M. Co-gestão ou parceria. A atuação da FUNATURA no Parque Nacional Grande Sertão Veredas - MG. In: Parcerias e co-gestão em unidades de conservação, 1.:1996:Brasília. Anais... Brasília: FUNATURA, 1996. p.23-29.

FUNDAÇÃO PRÓ-NATUREZA. Programa GSV. Programa Grande Sertão Veredas. Brasília: FUNATURA/FBPN. 1995. 10p.

FUNDAÇÃO VITÓRIA AMAZÔNICA. Plano de manejo do Parque Nacional do Jaú. Manaus: 1998. $266 \mathrm{p}$.

FUNDAÇÃO VITÓRIA AMAZÔNICA. Relatório técnico final. Parque Nacional do Jaú - projeto comunitário e projeto janelas para a biodiversidade. Manaus: 1999. 66p.

GUIDON, N. Parque Nacional Serra da Capivara. Co-gestão FUMDHAM / IBAMA. In: PARCERIAS E CO-GESTÃO EM UNIDADES DE CONSERVAÇÃO, (1.:1996:Brasília). Anais.... Brasília: FUNATURA, 1996. p.31-35.

GUIDON, N. Entrevista concedida à Shirley Noely Hauff. São Raimundo Nonato, 9 ago. 2001.

HAUFF, S. N. Relações entre comunidades rurais locais e administrações de parques no Brasil: subsídios ao estabelecimento de zonas de amortecimento. Curitiba, 2004. 225p. Tese doutorado em Ciências Florestais. - Setor de Ciências Agrárias, Universidade Federal do Paraná.

HOMMA, K. O. Amazônia: os limites da opção extrativa. Ciência Hoje, Rio de Janeiro, v.27, n.159, p.70-73, abr., 2000.

JORGE PÁDUA, M. T. J. Sistema Brasileiro de Unidades de conservação: de onde viemos e para onde vamos? In: CONGRESSO BRASILEIRO DE UNIDADES DE CONSERVAÇÃO, Anais... Curitiba: IAP, v.1, 1997. p.214 - 236.

KAMSTRA, J. Protected Areas: towards a participatory approach. 2.ed. Amsterdam: Netherlands Committee for IUCN. 1994. 55p.

LEWIS, Poblacion y parques en conflicto: un marco de analisis y accion. In: MOORE, A. Manual para

FLORESTA, Curitiba, PR, v. 35, n. 2, mai./ago. 2005 
la capacitación del personal de áreas protegidas: Tema 7: Manejo de recursos naturales y el público. Washington: National Park Service. 1993. p.H1-14.

LUCAS, P. H. C. Protected Landscapes: A guide for policy-makers and planners. The IUCN Protected Areas Programme. London: Chapman \& Hall. 1992. 297p.

MACKINNON, J. Integrando las áreas protegidas dentro del uso regional. In: MOORE, A. Manual para la capacitación del personal de áreas protegidas. Tema 7: Manejo de recursos naturales y el público. 2v. Washington: National Park Service, 1993. p.C1-4.

MILLER, K. Planificación de parques nacionales para el desarrollo en Latinoamerica. Madri: FEPMA. 1979. 500p.

MILANO, M. S. Conservação "in situ" e sistemas de unidades de conservação: Estratégias de conservação da biodiversidade. Brasília: 1991. 45p.

MILANO, M. S. Planejamento em unidades de conservação: um meio e não um fim. In: CONGRESSO BRASILEIRO DE UNIDADES DE CONSERVAÇÃO, Anais... Curitiba: IAP, 1997. v.1, p.150-165.

MOORE, A. Manual para la capacitación del personal de áreas protegidas: Tema 7: Manejo de recursos naturales y el público: Como hacer el extensionismo. Washington: National Park Service,1993. p.A1-6.

OLDFIELD, S. Buffer zone management in tropical moist forest: Case studies and guidlines. The Iucn Tropical Forest Programme. Gland: IUCN,1988. 49p.

PINHEIRO, M. R. Apresentação do Parque Nacional do Jaú como uma área natural a ser inscrito como Sítio do Patrimônio Mundial da UNESCO. Manaus: FVA, 1999. 31p.

SÃO PAULO. Secretaria do Meio Ambiente. Planos de Manejo das unidades de conservação. Parque Estadual da Ilha do Cardoso - Fase 1. São Paulo: 1998. p.3 - 48. Projeto Preservação da Mata Atlântica/ KfW

SÃo PAUlO. Secretaria do Meio Ambiente. Plano de Manejo Fase 2 - Parque Estadual da Ilha do Cardoso. São Paulo, 2001.. 134p. Projeto Preservação da Mata Atlântica/ KfW

SCHAIK, C. VAN.; RIJKSEN, H. D. Projetos integrados de conservação e desenvolvimento: Problemas e potenciais. In: TERBORGH, J.; SCHAIK, C. VAN.; DAVENPORT, L.; RAO, M. Tornando os parques eficientes: Estratégias para a conservação da natureza nos trópicos. Curitiba: UFPR/Fundação O Boticário. 2002. 518p.

The World Conservation Union. Parques y progreso. Washington, 1993. 258p.

The World Conservation Union. Parks for live: Report of the IVth World Congress on National Parks and Protected Areas. Gland, 1993a. IUCN. 260p.

VALARELLI, L. L.; ZANETTI, L. Avaliação do projeto Veadeiros - ACVCV - ASFLO - ASJOR WWF. Relatório Final. Rio de Janeiro: WWF-Brasil, 1998. 35p.

WELLS, M.; BRANDON, K.; HANNAH, L. People and parks. Linking protected area management with local communities. Washington: The World Bank, 1992. 99p.

WWF - Fundo Mundial para a Natureza. Chapada dos Veadeiros: estabelecimento de um projeto integrado de conservação e desenvolvimento no Cerrado brasileiro (PICD). Brasília: Brasil. 42p.

WWF - Fundo Mundial para a Natureza. Avaliação Final do Projeto Veadeiros. Brasília: WWF Brasil. $34 \mathrm{p}$. 